\title{
SEM Study of Corrosion Deposits of Ni-Mn-Ga Fe Doped Shape Memory Alloys
}

\author{
M. Sanchez-Carrillo ${ }^{1}$, H. Morales-Rodriguez ${ }^{1}$, J. P. Flores de los Rios ${ }^{2}$, E. Huape-Padilla ${ }^{3}$, A. Santos- \\ Beltran $^{1}$, and V. Gallegos-Orozco ${ }^{1}$ \\ 1. Universidad Tecnológica de Chihuahua Sur, Chihuahua. Chih. México. \\ 2. Facultad de Ingeniería, Universidad Autónoma de Chihuahua, Chihuahua, Chih., México. \\ 3. Facultad de Ingeniería Mecánica, Universidad Michoacana de San Nicolás de Hidalgo, Morelia, \\ Mich., México.
}

The alloys of the system $\mathrm{Ni}-\mathrm{Mn}$ - Ga close to the stoichiometric composition 2-1-1 are type Heusler structure alloys. These alloys exhibit a martensitic transformation which is related to the shape memory effect. Alloys near stoichiometric composition $\mathrm{Ni}_{2} \mathrm{MnGa}$ composition, has been increasing interest due to the wide range expected applications $[1,2]$. However, the fragility of this material is a limiting factor for practical applications. Cherechukin et al [3] reported that low doping of $\mathrm{Fe}$ in $\mathrm{Ni}-\mathrm{Mn}$ - $\mathrm{Ga}$ alloys enhancing the toughness of the material without sacrificing magnetic and thermoelastic properties. From the various samples tested (see Fig. 1 to 3), it is clearly noted that the attack was very aggressive for these cases showing a general dissolution without the presence of a localized attack; while in Fig. 2 particularly, a kind of crater or bump with a reservoir or crusting was observed. Corrosion deposits were found in alloys which are shown in Fig. 3 to be a little more uniform and somewhat porous in some areas, compared to the other cases (possibly attributed to an increased amount of Fe doping). For the case of Fig. 1b with fewer Fe containing doping, oxide presents a morphology with some flakes shaped deposits and some uncovered areas by those deposits. The material was analyzed by energy dispersive spectroscopy X-ray (EDS) to identify the elements present on the deteriorated surface and some selected areas. Fig. 1 has a general EDS where, according to the values in the table, there is a substantial amount of Ni and Mn such as $\mathrm{Na}, \mathrm{Cl}$ and $\mathrm{O}$. Fig. 2 shows the analysis of two zones: with (Zone 1) and without (Zone 2) a deposit. Zone 1 is constituted mainly of $\mathrm{Na}, \mathrm{Cl}, \mathrm{Ni}$ and $\mathrm{O}$, with $8 \%$ by weight of $\mathrm{Mn}$; while Zone 2 presented higher percentages of $\mathrm{Ni}, \mathrm{Mn}, \mathrm{Ga}$ and lower percentages of $\mathrm{Fe}, \mathrm{Cl}$ and $\mathrm{O}$ of about $1 \%$ by weight. The results obtained for the $2.1 \%$ Fe alloy are shown in Figure 3, which indicates that the highest percentage elements present in the analyzed surface were $\mathrm{Ni}, \mathrm{Na}, \mathrm{Cl}, \mathrm{Ga}, \mathrm{Mn}$ and the lower percentages were $\mathrm{Fe}$ and O.

Thanks to SEM and the EDS, analysis was possible to identify the corrosion deposits present in the material and proved to be an excellent tool for microstructural characterization of nanomaterials.

\section{References:}

[1] K. Ullakko, J. Huang, C. Kantner, R. O’handley, V. Kokorin, Applied Physics Letters, 69 (1996) 1966.

[2] P. Mullner, V. Chernenko, G. Kostorz, Journal of applied physics, 95 (2004) 1531-1536.

[3] A. Cherechukin, I. Dikshtein, D. Ermakov, A. Glebov, V. Koledov, D. Kosolapov, V. Shavrov, A. Tulaikova, E. Krasnoperov, T. Takagi, Physics Letters A, 291 (2001) 175-183. 

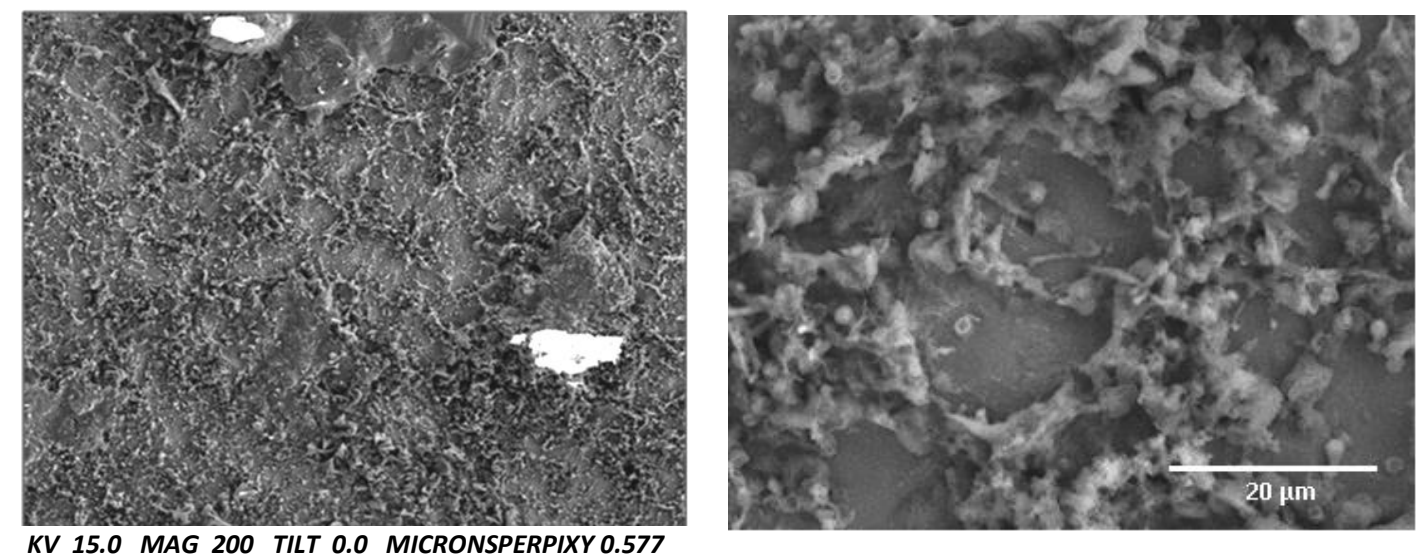

Figure 1. SEM image and EDS general result after the electrochemical test for $0.9 \% \mathrm{Fe}$ alloy, b) same alloy at 2000x.
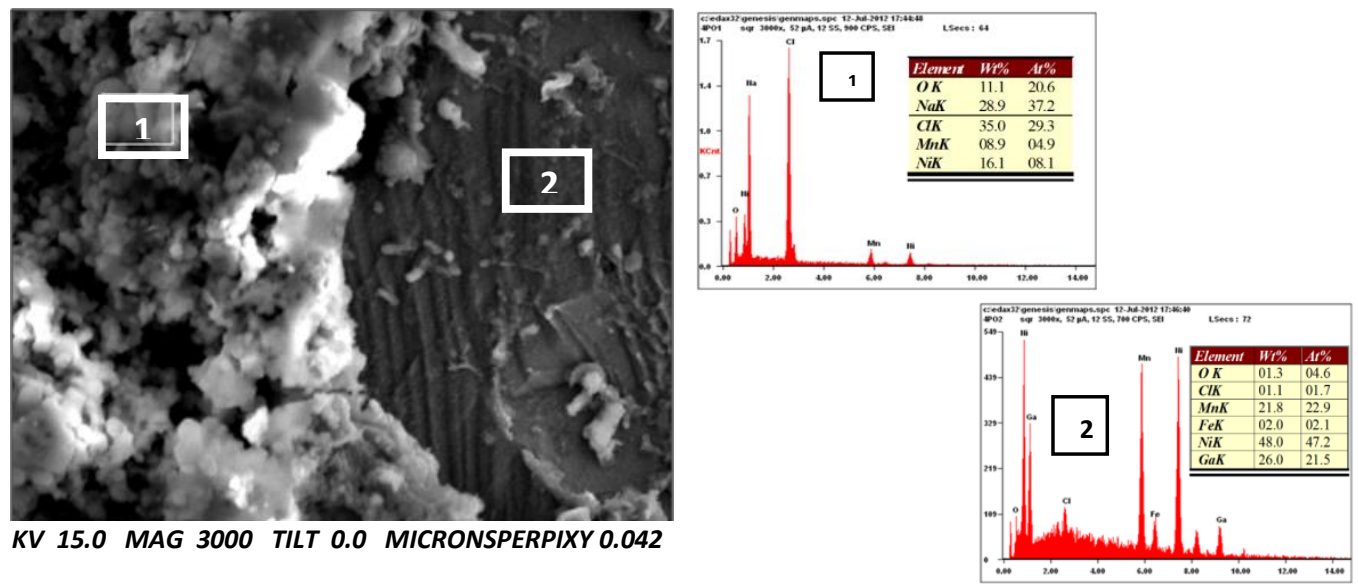

Figure 2. SEM image and general EDS results after electrochemical test for $1.7 \%$ Fe alloy.
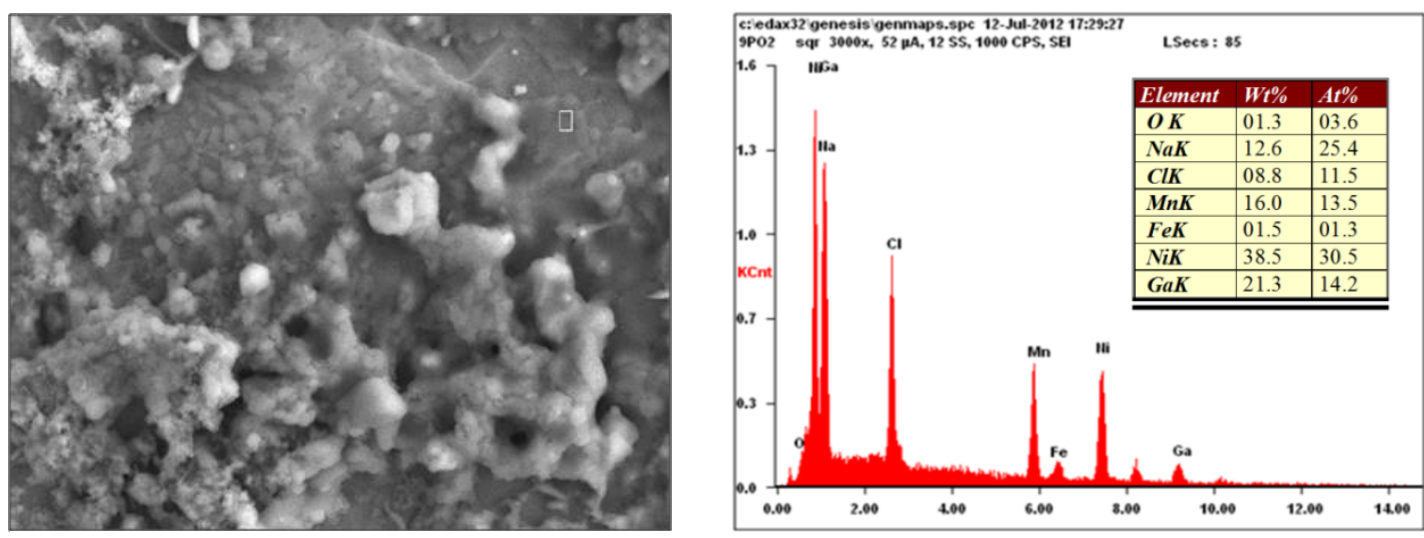

KV 15.0 MAG 3000 TILT 0.0 MICRONSPERPIXY 0.042

Figure 3. SEM image and EDS result after electrochemical assay for the alloy with $2.1 \% \mathrm{Fe}$. 